\title{
EN BUSCA DE FROYLÁN TURCIOS: APUNTES SOBRE LA VIDA Y OBRA DE ARMANDO MÉNDEZ FUENTES
}

\author{
Darío A. Euraque Méndez, Ph.D. \\ Associate Professor \\ Departament of History \\ Trinity College, Hartford, Connecticut, U.S.A.
}

\begin{abstract}
RESUMEN
Este ensayo resume un proyecto biográfico de la vida de un gay hondureño, Armando Méndez Fuentes (1925-2003). Méndez Fuentes, escritor y poeta inédito, vivió un exilio cultural en Nueva York desde 1953. Inicialmente se dedico a investigar la vida de Froylan Turcios (1874-1943), otrora aliado del General Augusto Sandino, y uno de los mas importantes escritores de Honduras del siglo XX. La vida y obra de Méndez Fuentes es un texto para analizar y narrar aspectos de la historiografía sexual centroamericana que aun permanecen inéditos, especialmente la historiografia de las masculinidades en el siglo $\mathrm{XX}$.
\end{abstract}

Descriptores: Escritor. Armando Méndez Fuentes. FroylánTurcios. Homosexualidad. Masculinidades. Honduras. Siglo XX.

\section{INTRODUCCIÓN}

En 1940, ya en el ocaso de su vida, exiliado y enfermo, Froylan Turcios, este otrora abanderado del General Augusto Sandino, redactó un párrafo titulado, "La Vida del Pasado." (Turcios 1940). Entre otras cosas decía entonces Turcios: "El que vive en una vieja ciudad- respetada por la civilización- y cultiva las rosas del sueño, siente, con mayor amargura el paso de los años. Cada sutil recuerdo, cada ladrillo milenario, cada gárgola, pétrea, cada objeto secular, pesan sobre él con la aniquiladora fuerza del Tiempo 
implacable. El pensamiento y el espíritu sufren este amargo mal del pasado, y, en la obra de arte, se tornan herméticos y taciturnos." Aun sin ser discípulo de Marcel Proust, los citados pensamientos de Turcios se prestan para introducir nexos entre el personaje central de este trabajo, Armando Méndez Fuentes, Froylan Turcios, y yo, tomando en cuenta por supuesto las evidentes proporciones intelectuales. Este ensayo no es una autobiografía, pero si goza, o sufre dirían otros, elementos de ese género.

Hace ya casi tres años que leí una larga biografía del gran novelista francés Marcel Proust (Carter 2000). La leí por muchas razones. Por un lado, leí la biografía porque Proust, enriqueciendo la teorización de la historiografía, nos ofreció a comienzos del siglo pasado una de las primeras aproximaciones serias sobre la complejidad de la memoria histórica como experiencia individual y su yuxtaposición con la memoria social. Me interesó esa dimensión de Proust leyendo otro libro, uno titulado, Como Recuerdan las Sociedades y escrito por el historiador inglés Paul Connerton (1989). Connerton recurre a Proust, quien vivió entre 1871 y 1922, y extrajo de su gran novela, En Busca del Tiempo Perdido, conversaciones entre personajes que de una u otro manera abordan la relevancia del pasado para con el presente destilado en la narrativa de la novela en sí.

Me interesa esta problemática porque mi nuevo proyecto después de terminar con mis más reciente libro sobre la historia del mestizaje en Honduras (Euraque 2004) tiene que ver con la vida y obra de un hombre desconocido pero ejemplar, Armando Méndez Fuentes; entre otras hazañas, Méndez Fuentes rescató valiosísimas fotografías de Froylan Turcios y algunos de sus familiares. ¿Quién fue Armando Méndez Fuentes? Comencemos citando una carta que me dirigiera Méndez Fuentes en 1968. Gozaba yo de ocho años. 
"...Tu abuelita me ha hablado tanto de ti, me ha dicho tantas cosas buenas tuyas que por eso yo te quiero mucho. Te quiero también porque eres muy inteligente. Marcelito Proust se llamaba un delicado niño francés que también era enfermo de asma....pórtese bien con los libros, los animalitos y las plantas porque cada día te enseñaran muchas cosas y será tu excelente imaginación como la de un maestro de la prosa como la del niñito francés Marcelito Proust que quería mucho a su abuelita..."

En Febrero de 1968 Armando Méndez Fuentes tenia ya casi 20 años de vivir en Nueva York, habiéndose trasladado a Manhattan en calidad de residente en 1953, a los 28 años. Yo en 1968, recién emigrado con mi familia a Nueva Orleáns en diciembre de 1967, no sabía entonces quien era Marcel Proust, ni tampoco le di atención alguna ha aquel insigne personaje literario. Si me llamó la atención el interés que el hijo mayor de mi abuelita, Doña María Fuentes Osorio, el hermano mayor de mi mamá, le diera respuesta a una carta que yo le enviara a ella desde Nueva Orleáns. Desde ese entonces creí importante conservar esa carta; comenzó así mi un apego a los papeles viejos que mas tarde me llevaría no solo a conocer mas a fondo a Armando Méndez Fuentes, sino también a papeles y fotografías viejas que Armando Méndez Fuentes conservara durante décadas, y que me heredara en Septiembre del 2000.

Continuemos con Marcel Proust. En Abril de 1968, pocos meses después que mi tío me enviara la carta ya citada, le escribió una carta a Merceditas Turcios, una de las hermanas menores de Froylan Turcios y que aun vivía en Tegucigalpa. La misma es importantísima por muchas razones. Por ello la cito in extenso:

"...Mi querida e inolvidable amiga. Usted que ha sido amiga fiel y compañera constante mía, como buscadores de recuerdos, de cartas, de fotos, de frases y pensamientos de su hermano, el poeta nunca olvidado don Froylan Turcios... Pareciera que usted y yo fuéramos dos personajes más de la obra novelesca del escritor francés que tanta influencia tiene su obra en la literatura contemporánea, 
"En Busca del Tiempo Perdido” de Marcel Proust. ¡Cuantas cosas destruye la vida! ¡Cuantas cosas mata furtivamente el destino! ¡Cuantos seres humanos con sus herencias, riquezas, papeles y cosas pierde, confunde y finalmente destruye el tiempo. Mas por medio del arte, de mi trabajo y de mi perseverancia todavía embalsamada de ese encanto constructor que sólo los verdaderos artistas poseemos el secreto vivo, tenaz y edificante para poder terminar algún día con belleza la obra difícil que empezamos podré salvar dignamente la obra literaria, patriótica y amorosa de su hermano en mi estudio biográfico de su vida espléndida..."2

Esta carta esta cargada de importantes datos que sin duda ofrecen respuestas aproximadas a ciertas interrogantes. Deseo puntualizar algunos elementos de la carta. Primero, la profunda vocación que muestra Armando Méndez Fuentes para con la memoria histórica individual como un valor central de la vida cotidiana. Segundo, la fundamentación de ello en la gran novela de Marcel Proust. Tercero, la profunda amistad que enlazaba desde antaño a Méndez Fuentes con Merceditas Turcios y también entre ella y mi abuelita. Cuarto, es importante rescatar también de esta carta el compromiso de Méndez Fuentes para con la vida y obra de Froylan Turcios más de 25 años después de la muerte de aquel escritor.

De hecho, el archivo privado de Méndez Fuentes, también ya en mis manos, registra que desde 1952 se comprometió con investigar y algún día publicar una biografía literaria de Turcios titulada, Froylan Turcios, Gloria Continental. ${ }^{3}$ Para ese entonces estaba Turcios ya casi olvidado en la historia literaria de Honduras. De hecho, no fue sino hasta las décadas de 1970 y 1980 que se redactaron estudios serios sobre Turcios, simultáneamente a la resignazion por parte de Méndez Fuentes que quizás el nunca redactaría la obra con que se comprometió a comienzos de la década de 1950 (Duron 1973; Mejia 1980; Arita Palomo 1983). Después de la muerte de Turcios en Costa Rica en 1943 se publicaron numerosos artículos en revistas y periódicos, pero carecemos aun 
de un trabajo exhaustivo y complejo, especialmente dentro del mas estrecho genero de una "biografía literaria". ${ }^{4}$ Solo el año pasado por fin se presento la primera tesis doctoral sobre Turcios (Funez 2003). ${ }^{5}$

Armando Méndez Fuentes, por complejas razones que quizás abordare yo un día en su biografía, nunca pudo terminar su biografía literaria de Froylan Turcios y otras que proyectaba, una titulada, Froylan Turcios y España y otra titulada, Cartas de Froylan Turcios. Aun en 1990, en varias cartas dirigidas a Jorge Fidel Duron, eminente hombre de letras de Honduras, pedía Méndez Fuentes un "prólogo" para una obra ya abandonada. Esta ultima se fundamentaría en una valiosa documentación que Méndez Fuentes también rescató por medio de Merceditas Turcios y otros familiares, y que pasó ahora a mis manos. No obstante, Méndez Fuentes sí redacto varios ensayos breves pero importantes sobre Turcios, casi todos aun inéditos. Los siguientes títulos son importantes:

"El Suicidio Premeditado de Froylan Turcios"

"Estela Becerra Turcios de Pineda Ugarte"

"Correspondencia Entre Lucila Gamero de Medina y el Poeta Froylan"

"¿Como Conoció Froylan Turcios a Rubén Darío"

"Froylán Turcios en la Opera de París"

Durante las décadas de 1970 y 1980, Méndez Fuentes, "biógrafo autodidacta” se autocaracterizaba entonces, hizo esfuerzos por comunicarle sus inquietudes y proyectos a importantes intelectuales de Honduras, desde Leticia Oyuela hasta Juan Ramón Martínez, ambos reconocidos historiadores de la cultura hondureña. Estos intelectuales, ambos 
amigos míos, Oyuela en especial, no tomaron en serio los proyectos de Méndez Fuentes. ${ }^{6}$ En 1991 el ofreció una charla fundamentada en su aun inédito ensayo titulado, "El Suicidio Premeditado de Froylan Turcios" (Méndez Fuentes 1991).

Sin embargo, durante los próximos años Méndez Fuentes no solo abandonó su viejo compromiso biográfico con Turcios, sino que entró en una crisis emocional e intelectual que lo llevo a dedicarse casi por completo al estudio de su religión de infancia, la Adventista, y entonces con un nuevo compromiso de elaborar una obra de reflexiones sobre teología escatológica. Ya para fines de la década de 1990 sus poemas y ensayos inéditos se llenaron de reflexiones sobre sus "pecados", y su arrepentimientos por haber sido "una oveja descarriada."7 Nos declara en un poema de esa época:

“...Morar deseo con El Divino Quijote una eternidad. Jamás hirió como los hombres mi sensibilidad. ¡Oh Amor incomparable entre todos los amores! Amor eterno de bella y fácil compenetración. Dulcemente delicado como una santa oración, El sana maravilloso todos mis dolores.

Morar con El Divino Quijote, fuente de infalibilidad, Para los pecadores ateos eres una impenetrabilidad. Divino Quijote Omnipotente que puedes apagar El Universo, Sediento estoy de tu amor y santidad... ¡Este discípulo implora perdón, humildad, gnosticismo y aceptación para mis versos! $!^{8}$

Mientras tanto, durante la década de 1980 yo seguí con mis estudios, y para 1990 termine con mi tesis doctoral, y otros estudios, sobre la historia social y económica de la Costa Norte de Honduras (Euraque 1996 a,b,c). A mediados de la década de 1980 aun conservaba la carta que Méndez Fuentes me envió en 1968 cuando contaba yo con ocho años. Presumiendo estar listo para hacerle saber a mi tío que quizás pudiésemos continuar 
nuestra correspondencia de nuevo, comencé a enviarle mis publicaciones sobre la historia de Honduras. Ello despertó en mi tío aquel mismo interés que me mostró cuando a los ocho años le envíe una carta a mi abuelita.

Así, desde mediados de la década de 1980 hasta la actualidad nos reencontramos, yo un poco mas maduro, (creo) y el también. Para ese entonces mi abuelita me relataba anécdotas de la vida de Froylan Turcios y sus hermanas (hasta su deceso en 1996, ella hizo memoria de Turcios y sus hermanas). Esas conversaciones, conversaciones entre memorias diría Marcel Proust, también provocaron mi curiosidad sobre Turcios, y la memoria histórica y el individuo. Así comencé desde 1998, a esbozar un proyecto biográfico de mi tío, proyecto para el cual me heredo su documentación privada, y también la que el heredó sobre el literato Turcios de parte de Merceditas Turcios.

En esa coyuntura también me motivo mucho la preparación de una larga reseña que redacté del libro de Rocío Tábora sobre la masculinidad en Honduras (Euraque 1996d; Tábora 1995). Si bien aquel texto fue y sigue siendo innovador, sigue vigente la siguiente crítica: si la masculinidad patriarcal se fundamenta en la opresión de mujeres, mediante regímenes y códigos culturales, este mismo sistema también se autolegitíma mediante la exclusión, y con frecuencia, violenta, de no sólo la homosexualidad, sino también de todo aquello que tenga semejanza con lo "femenino", pero asumido por el varón.

Por ejemplo, en 1949, Angel Zúñiga Huete, el máximo intelectual del Partido Liberal en aquella época, en un folleto que Tábora cita, enjuicio el aparente "transfuguismo" político del poeta e historiador Rafael Heliodoro Valle (1891-1959) en una "semblanza" en la cual su aparente homosexualismo sirve como el blanco de la indignación machista del ideólogo 
Liberal. Desafortunadamente, Tábora aquí menosprecio un excelente texto para indagar sobre un importante aspecto de la subjetividad masculina patriarcal. ${ }^{9}$

De todas maneras, ahora una lectura preliminar de esa documentación me ha mostrado a Armando Méndez Fuentes como un personaje complicado, interesantísimo, cuyo valor reside no solo en haber en conservado fotografías y documentos de Froylan Turcios, sino que reside también en el archivo privado de Méndez Fuentes. El mismo conserva muchos poemas y ensayos, de muy variada calidad, que abordan importantísimos temas de la condición humana, desde la memoria histórica hasta la homosexualidad y la estética de un hombre gay autodidacta. De hecho, en su archivo se pueden abordar los llamados "silencios alrededor de la sexualidad" (Wrathall 2000).

Así pues, la vida y obra de Armando Méndez Fuentes se presta para documentar problemáticas conceptuales y de investigación que durante las ultimas décadas se han generado dentro de la historiografía de la sexualidad y genero pero que con raras ocasiones se pueden evidenciar sistemáticamente (Weeks 2002). De hecho, creo que la vida y obra de Méndez Fuentes es una especie de texto donde se pueden explorar a profundidad, con detalle histórico, construcciones de la masculinidad en contextos transnacionales latinoamericanos (Foster 2002: 163). Este ensayo representa sólo apuntes mínimos para un proyecto biográfico que llevara muchos años.

\section{PROSOPOGRAFÍA Y OBRA DE ARMANDO MÉNDEZ FUENTES}

Para los propósitos de esta corta presentación, creo conveniente delimitar la vida y obra de Armando Méndez Fuentes en tres etapas: una que abarca su nacimiento y vida previo a su primera llegada a Nueva York en 1949; otra etapa abarca, primero, su 
regreso de Nueva York a Honduras a fines de 1950, y luego su traslado de nuevo a Nueva York en 1953, y hasta 1971. Durante esta etapa explora plenamente la vida bohemia y literaria en Nueva York, y publica algunas escritos al respecto, en Nueva York y en Honduras. En 1971 regresó a Honduras otra vez, luego de lo que en una carta llamara su "exilio voluntario" de casi veinte años.

Por último, creemos poder delimitar un largo periodo de casi treinta años cuando Méndez Fuentes transitó entre un apego a una vida literaria autodidacta con tintes de una estética homosexual, y un arrepentimiento religioso que al final de sus días negó, contradiciendo importantes valores que predicó casi toda su vida. Los siguientes apuntes ofrecen breves reseñas de estos periodos en la vida y obra de Armando Méndez Fuentes.

\section{a. Nacimiento y la decisión de abandonar Honduras, 1925-1951}

Armando Méndez Fuentes nació en Tegucigalpa el 13 de Marzo de 1925, en la casa de su tío paterno, Rafael Osorio Jirón, dueño entonces de una tienda llamada la Anglo-Americana, donde compraban sus vestimentas los mejores caballeros de la alta sociedad de Tegucigalpa. Sus padres fueron, María Osorio Fuentes y Gregorio Méndez Jiménez, Salvadoreño, y otrora sastre maestro en una tienda que tenía Rafael Osorio Jirón en El Salvador.

Méndez Fuentes desde niño escucho muchas conversaciones de su tío y su madre sobre los quehaceres de la alta sociedad de Tegucigalpa, y también de personajes particulares, incluyendo Froylan Turcios, cuya hermana mayor, Lalita, de hecho su predilecta, fue muy amiga de la madre de Méndez Fuentes. También las hermanas 
menores de Froylan Turcios fueron intimas de María Osorio Fuentes. Fue por medio de esas conversaciones y acceso a los libros de Turcios en manos de sus hermanas en Tegucigalpa que Armando Méndez poco a poco cultivo un apetito por la literatura universal en un medio donde escaseaban las influencias internacionales en las escuelas.

Ya para la fines de la década de 1930, el padre de Méndez Fuentes, Don Gregorio, se convirtió en Adventista, trayectoria religiosa que su madre nunca acepto, y que hasta al final marco la vida de Méndez Fuentes. Ya para comienzos de la década de 1940, Méndez Fuentes, como todos los siete hijos de Don Gregorio, asistían a la Iglesia Adventista y sus escuelas financiadas y administradas por pastores alemanes. Por lo tanto, mientras Méndez Fuentes exploraba los grandes temas de la condición humana en los escritos de Turcios y otros, también se veía bajo la enorme influencia de los Adventistas, cuyo conservadurismo religioso y cultural no cabalgaba con las ideas de Turcios y otros.

Es más, ya para mediados de la década de 1940, Méndez Fuentes, según entrevistas, estaba convencido que su atracción emocional y sexual no era por las niñas y jóvenes féminas, sino por los varones como el. Fue con esas contrariedades que en 1949 se marchó para estudiar teología Adventista en Massachusetts en los Estados Unidos. Viajaba con fondos de los Adventistas. Descansó una semana en Nueva York con una familia Puertorriqueña a fines de 1949; previo a su emigración final hacia el norte en Massachusetts, contando con 24 años, se empapó de la vida nocturna de Manhattan, incluso de su entorno gay. De hecho, sus recuerdos de esa época en Manhattan se asemejan mucho a la historia social del mundo gay de Nueva York tal como lo reconstruye el importante historiador George Chauncey (1994). 
Ya para fines de 1950, Méndez Fuentes abandono sus estudios en Massachusetts, y decidió regresar a Honduras por tierra, por medio de México, Guatemala y El Salvador. Este viaje de meses fue decisivo en los cambios que surgieron durante esa década. Durante el trayecto visitó, motivado por la audacia individual, importantes literatos, poetas, artistas y bohemios en casi todas las grandes ciudades de estos países. En el trayecto conoció hasta a Diego Rivera; en Guatemala se entrevisto con el gran violinista hondureño Humberto Cano. Comenzó también una extensa correspondencia con Froylan Castellanos, un viejo intelectual de Juticalpa, capital del Departamento de Olancho y quien conoció de cerca a Turcios y a su tío Rafael Osorio Jirón.

\section{b. Nueva York y las incursiones literarias en la estética Gay, 1951-1971}

Para mediados de 1951, ya en Tegucigalpa, Armando Méndez Fuentes había decidido abandonar Honduras y regresar a Nueva York. Viajo hasta 1953. Los preparativos comenzaron a inicios de 1952, año decisivo y de crisis emocional e intelectual. Contaba con 26 años. Las primera referencias impresas sobre y por Méndez Fuentes aparecieron en Honduras en 1952.

Durante aquel año, se publicaron en periódicos en Tegucigalpa, San Pedro Sula y Tela diferentes comentarios sobre Méndez Fuentes relacionados con su proyectado viaje a Nueva York, el cual se consideraba como un tipo esfuerzo cultural de parte de un joven escritor e intelectual que buscaba mejores horizontes. La documentación en mis manos registra artículos cortos de importantes nombres en el mundo literario de la época, desde Froylan Castellanos hasta la poetisa Angela Ochoa Velázquez. 
Estos y artículos propios de mano de Méndez Fuentes hacían referencia a varios proyectos con que se hallaba comprometido: una biografía de Froylan Turcios; y una biografía titulada La Maestra que Defiendo. La maestra ha que se refería Méndez Fuentes era Soledad Fernández Cruz, a quien conoció en San Pedro Sula en 1941 o 1942. A comienzos de aquella década, Gregorio Méndez traslado la familia a San Pedro Sula en haras de establecer un negocio que pronto fracasó. Méndez Fuentes durante ese año conoció a Fernández Cruz, una escritora y maestra que durante la década de 1920 viajó a Nueva York y otras importantes ciudades de las Américas y se relacionó con importantes intelectuales de la época, incluyendo a José Vasconcelos. De hecho, Méndez Fuentes parece haber considerado a Fernández Cruz como una especie de Gabriela Mistral, de hecho con ciertos de los compromisos sexuales que se le atribuyen a la poetisa Chilena (Fiol-Matta 2002) , a quien Méndez Fuentes conoció y entrevisto a Mistral en Nueva York en la década de 1950.

A pesar de haber publicado varios textos escolares, ya para 1942 Fernández Cruz se sentía marginada e incomprendida en el ambiente provinciano de Honduras. Era soltera, y carecía de hijos, y se dedicaba por completo a una "escuela-granja" y los estudiantes que solían visitarla. La escuela-granja era una especie de jardín botánico adornado con riachuelos donde se bañaba y luego se leía literatura universal; allí muchachos inquietos e intelectuales como Méndez Fuentes encontraban sustento emocional entre sí y al pie y labios de la maestra Fernández Cruz y sus inspiraciones. Según Méndez Fuentes, durante ese año y otras visitas, Fernández Cruz lo llego a considerar su "estudiante predilecto." Es mas, un documento legal de la época evidencia que en Junio de 1951 Fernández Cruz 
le heredó a Méndez Fuentes su documentación privada para que este algún día escribiera su biografía.

Este proyecto, así como la biografía de Froylan Turcios, nunca prosperó. Es mas, durante la década de 1990, Méndez Fuentes incineró la documentación que heredó en 1951 de parte de Fernández Cruz. No obstante, en 1952, la relación con Soledad Fernández Cruz fue fundamental para el "exilio voluntario" que escogió Méndez Fuentes. A fines de ese año, su querida maestra fue asesinada por su propio hermano en la granjaescuela que tanto añoraban ambos. Méndez Fuentes, contrario a la familia y muchos amigos de Fernández Cruz, hizo lo posible para investigar los móviles del crimen, y se enfrascó en una polémica en los periódicos de San Pedro Sula y Tegucigalpa con una connotada escritora de la época, Graciela Bogran. Méndez Fuentes aseguraba que Bogran lo acompaño al sitio del crimen, donde encontraron testigos oculares que inculpaban al hermano de Fernández Cruz. Al final, no hubo investigación del caso.

Mientras tanto, además de este complicado trauma, Méndez Fuentes publico ciertos ensayos en Tegucigalpa que también registraron un muy publico distanciamiento del medio común en Honduras. Clave fue el hecho que en 1952 Méndez Fuentes publicó un ensayo sobre Oscar Wilde (1854-1900), el gran dramaturgo y esteta inglés, y además, quizás el primer intelectual homosexual que públicamente defendiera amores sexual entres hombres. En ese ensayo, Méndez Fuentes reconoce a Wilde como "esteta consumado" y que le supo cantar a los "secretos de las rosas" y a "la belleza desnuda y viril de un mancebo...." (Méndez Fuentes, 1952).

Méndez Fuentes también se refirio a Wilde "como verdadero poeta aristocrático [que] amaba con pasión el lujo." Es mas, reconocio la amistad efímera de Wilde con 
Walt Whitman, otro "maricon eminente" diría quizás un crítico latinoamericano (Manrique 1999). En 1952, Méndez Fuentes también declaró que Wilde “afirmó categóricamente que no podía compararse el cuerpo deformado de una mujer de enormes caderas grasientas con las líneas aladas de un joven adolescente.” Por ultimo, registró el hecho que Rubén Darío se refirió a Wilde en su autobiografía y que también José Martí registro detalles de Wilde en relatos periodísticos en la década de 1890.

Durante las décadas de 1950 y 1960, en Nueva York Méndez Fuentes aprendió inglés y trabajo como enfermero, especialmente atendiendo el cuidado de ancianos en hospitales en Manhattan. Mas importante aún para nuestros propósitos, Méndez Fuentes continuo su educación autodidacta en las bibliotecas de Nueva York y también poco a poco construyo una importante biblioteca personal colmada con las grandes novelas Europeas. También se alimento culturalmente con los diarios de viaje de eminentes Europeos, especialmente cuando viajaban a los continentes de Asia y Afrecha. Méndez Fuentes aprendió a tocar el piano, compro su propio piano, y también aprendió a tocar el violín. En pocas palabras, vivió, dentro de sus medios, y con las limitaciones de una educación muy informal y ad hoc, como un "esteta consumado".

Su orientación sexual y su relación con escritos y proyectos literarios más allá de las biografías de Turcios y Fernández Cruz también pueden marcarse bien, por lo menos de manera preliminar para estos apuntes. A mediados de la década de 1960, estableció una amistad epistolar con Luis Hernán Sevilla Gamero, un historiador y seminarista y sobrino de una gran novelista hondureña, Lucila Gamero de Medina. Esa relación epistolar comenzó por medio de amigos de Méndez Fuentes en Tegucigalpa que conocían sus inclinaciones literarias y amorosas. ${ }^{10}$ Fue Luis Hernán Sevilla quien le publicó en 
Tegucigalpa a Méndez Fuentes su primer poema homoerótico, titulado, "Cuando tu Regreses.” Aquí algunos de sus versos.

“...¡A Amado mío, cuando tú regreses celebraremos una gran fiesta de amor....! Iremos descalzos sobre los verdes campos alfombrados de pino, hierba y hojas secas.

Recogeremos flores perfumadas y haremos lindas guirnaldas para nuestros cuellos. Tú me coronaras y yo te coronaré con los lotos rojos y rosas blancas como en las antiguas fiestas romanas..."11

Durante la década de 1960, entre el fervor de los diferentes movimientos liberales y radicales en Nueva York, incluyendo la llamada "revolución sexual" de la época, Méndez Fuentes se comprometió con otro proyecto literario que tampoco gozó de éxito. Méndez Fuentes buscaba publicar en Honduras un pequeño poemario homoerótico titulado Lotos del Pantano. ${ }^{12}$ Sin embargo, para este caso gozamos de una documentación muy particular que evidencia quizás la razón más poderosa que le puso fin a ese proyecto al terminar esa misma década. Comenzó todo con una carta enviada a un importante poeta hondureño, Luis Alemán, mejor conocido como Claudio Barrera.

En 1954, el galardonado con el Premio Nacional de Literatura "Ramón Rosa", en Honduras el máximo premio literario de la época, fue Claudio Barrera (1912 -1971) (Gold 2001: 163 y 173). Varias antologías y criticas reconocen a Barrera como un poeta excepcional, miembro de la "Generación de la Dictadura", es decir, que surgieron publicando durante la dictadura del General Tiburcio Carías Andino (1933-1949) (Sosa 1987). Barrera fue amigo de Méndez Fuentes previo a su salida para Nueva York, y también fue amigo de la madre de Méndez Fuentes. Vivió en el mismo Barrio Buenos 
Aires donde Gregorio Méndez y María Osorio llegaron a vivir al llegar los hermanos menores de Armando.

En las décadas de 1930 y 1940 Barrera formó parte de un circulo literario bien definido de donde salieron las producciones que fundamentaron el galardón de 1954. En 1959, Barrera le envió a Méndez Fuentes su Poesía Completa, publicada en 1956. El libro lleva una dedicación de Barrera que dice: "Como un recuerdo cariñoso del viejo amigo que dejaste en esta tierra hondureña, que día a día espera que sus buenos hijos como tú le dignifiquen fuera de nuestras fronteras- Y no olvides las letras, el arte y los sueños."

Barrera murió en 1971 siendo agregado cultural de la Embajada de Honduras en España. Sin embargo, a fines de la década de 1960, desconocemos la fecha exacta, Méndez Fuentes le escribió a Claudio Barrera pidiéndole un "prólogo" para Lotos del Pantano. La respuesta de Barrera fue brutalmente negativa, y llego a Nueva York en forma de un poema titulado, "Epístola Intemporal." Armando Méndez Fuentes nunca publicó su Lotos del Pantano. A comienzos de la década de 1980 parece que todavía conservaba los poemas que formarían parte de ese poemario.

Aun en 1985, ya a punto de morir, Luis Hernán Sevilla Gamero le escribió a Méndez Fuentes indagando, “.....¿̨alguna vez publicarás tú libro? Ve, la vida es breve, y poca gente (familiares o herederos conservan manuscritos o papeles, no es raro que los destruyan). ${ }^{\prime 13}$ Creemos que la hiriente carta de Claudio Barrera fue fundamental para que Lotos del Pantano nunca se publicara. Es más, ya durante la década de 1990, Méndez Fuentes incineró la mayoría de esos poemas. Escuchemos versos de la amarga "Epístola Intemporal": 
“...Eres la bestia apocalíptica, suelta y desesperada

Entre el veneno horrible de la carne y el aguijón del espíritu.

Eres grito de muerte dilatado en un campo de terribles amargos.

Solo tú, con tu sombra impenitente, caminas lentamente

Por un jardín de lotos ignorados....Así siento tu voz, tu sentimiento

Vagando, como un loco en un país de amor deshabitado...."

\section{c. Ambigüedades y arrepentimientos, 1971-2001}

Méndez Fuentes fue fuertemente herido por la "Epístola Intemporal" de uno de las más conocidos poetas de Honduras. ${ }^{14}$ Le redacto una respuesta en verso a Barrera donde se registran algunos de los temas que sin duda se desarrollarian en Lotos del Pantano. Reproducimos algunos versos aquí:

“...Una vez mi casta juventud sonriente y sonora

Te mandó una carta bella como la aurora,

Con mi joyel de versos, "Lotos del Pantano."

¡Muy Feliz estaba, acudiendo a tu benevolencia;

te pedía un ensayo con gran reverencia

por mi canto ardiente que inspiró un hermano!...

Mi pluma dibujo escenas del mundo amoroso

Cuando Miguel Ángel, aquel Genio tan glorioso

A Tommaso Cavalieri adoraba apasionadamente...

Confiando, mi amigo Claudio, en tu noble loor,

Tu genio poético; más declaro que me causó horror tu

"Epístola Intemporal" que ofende injustamente.

Barrera, inocente cordero me llamaste "Bestia desesperada"

Porque tú no comprendiste la erótica llamarada de Walt Whitman,

El poeta de Nueva York....

Nosotros cantamos al joven, la niña virtuosa,

Al hombre infame, y á la mujer lujuriosa

Porque peca por el hambre y por su amor.

Jesús nos enseño a amar á los pecadores

Perdonar al miserable y comprender todos los amores.... 
Eso es nuestro cielo y nuestra primavera.

No maldecir al ofensivo y ser clemente,

Jesucristo agonizando perdonó muy paciente,

Y por eso lloró hasta la pantera..."

Años después de la correspondencia cruzada con Claudio Barrera, Méndez Fuentes compuso un poema en prosa titulado, "Lotos del Mundo," donde caracterizó su búsqueda por Lotos, y donde también caracterizó sus años después de salir de Honduras, como “...el pantano dramático de mi vida para lenificar esta incurable enfermedad de mi corazón..." Esta y otras declaraciones son triste testimonio que Méndez Fuentes nunca transito a aceptar su sexualidad gay de forma plena y natural. Es mas, como dejamos entrever al comienzo de estos apuntes, ya para la década pasada, al jubilarse en 1990, Méndez Fuentes entro en una crisis emocional que lo condujo de nuevo a la Iglesia Adventista, de hecho hasta bautizarse de nuevo.

Méndez Fuentes regresó a Honduras a comienzos de la década de 1970, ya después de muerto Claudio Barrera y así profundizo su amistad con Luis Hernán Sevilla. A mediados de la década buscó en vano que se le tomara en serio su proyecto biográfico sobre Froylan Turcios. Viajó a Honduras con frecuencia en la década de 1980, y hasta se propuso regresar a vivir allá permanentemente. Sevilla Gamero murió en 1988, el mismo año en que Méndez Fuentes y yo retomamos la correspondencia que se abrió en 1968, 20 años antes. Durante la próxima década lo aquejaron varias enfermedades de la vejez. Temio haber sido infectado por el VH-Sida, pero resulto que no. Se sentía solo y aislado y ya Manhattan no era el espacio libertador de antaño. Murió en Mayo del año pasado.

\section{CONCLUSIONES}


En Marzo de 1999, ya con 74 años, Méndez Fuentes me envió una carta junto con unos documentos. Dice la misma: "Le mando ese documento al obsequiarme el poeta Claudio Barrera su libro: Poesía Completa. Pasó el tiempo y una vez le pedí un prólogo para mi poemario Lotos del Pantano; por respuesta tuve una hiriente respuesta escrita en versos." Continua la carta así:

"Los audaces insultos y las sorprendentes polémicas hacen famosos a los libros y célebres raros a los autores osados, para sobrevivir quizás eternamente. Por consecuencia vale la pena investigar las sensaciones para llegar hacer una vívida celebridad en 24 horas, practicando con destreza aquellas afirmaciones verídicas del poeta Oscar Wilde: 'Alabando o Desprestigiando a Todo el Mundo'...”

Para ese entonces Méndez Fuentes había incinerado quizás buena parte de sus documentos y importante correspondencia intima cruzada con otros personajes más que Luis Hernán Sevilla Gamero. ${ }^{15}$ Vivía entonces Méndez Fuentes contrariado por una vida literaria y compromisos estéticos que quiso integrar con su sexualidad gay pero que no se ajustaba a las exigencias de la religión que nunca abandonó. De hecho, a escasos días de haber redactado la carta en que citaba a Oscar Wilde, me redactaba otra que registraba el otro polo de su contrariedad:

“...da la casualidad que he estado vendiendo y obsequiando la mayor parte de mis documentos y de mi biblioteca. Estoy de ahora en adelante completamente muy ocupado en la Escatología que es parte importante de la Teología y preparándome para ser bautizado en la verdadera religión del mundo y de su abuelo Gregorio Méndez..."

Si bien es cierto que de esta manera "La vida del pasado" pesaba aún en Méndez Fuentes, queremos dejar constancia, aunque nunca termine yo su biografía, que en su 
vida y obra Méndez Fuentes incursionó, venciendo límites de formación académica y de

otra índole, en senderos que todavía suelen ser misterio y tabú en Honduras: el erotismo, la sexualidad y la estética. ${ }^{16}$

\section{BIBLIOGRAFÍA}

Allyn, David. 2001. Make Love not War: The Sexual Revolution: An Unfettered History. New York: Routledge.

Arita Palomo, Carlos Manuel. 1983. Vida y obra de Froylán Turcios. Tegucigalpa: Editorial Universitaria.

Carter, William C. 2000. Marcel Proust: A Life. New Haven: Yale University Press.

Connerton, Paul. 1989. How Societies Remember. Cambridge: Cambridge University Press.

Euraque, Dario A. 2004. Conversaciones Históricas con el Mestizaje en Honduras y su Identidad Nacional. San Pedro Sula: Centro Editorial. 1996a. Estado, Poder, Nacionalidad y Raza en la Historia de Honduras: Ensayos. Tegucigalpa: Ediciones Subirana. . 1996b. Reinterpreting the Banana Republic: Region and State in Honduras, 1870-1972. Chapel Hill, NC: University of North Carolina Press.

1996c; 2001. El Capitalismo de San Pedro Sula y la Historia Política Hondureña (1870-1972). Tegucigalpa: Guaymuras, 1996; reimp. 2001. . 1996d. "Una Nueva Visión Sobre el Caudillismo y la Violencia Política en Honduras: Resumen y Comentario." Revista de Historia, Costa Rica (33): 187-200.

Fiol-Matta, Licia. 2002. A Queer Mother for the Nation: The State and Gabriela Mistral. Minneapolis: University of Minnesota Press.

Foster, David William. 2002. "The Homoerotic Diaspora in Latin America." Latin American Perspectives, Vol. 29 (2): 163-189.

Freedman, Estelle. 2001. "The Burning of Letters Continues: Elusive Identities and the Historical Construction of Sexuality." En Allida M. Black, ed., Modern American Queer History. Philadelphia: Temple University Press, pp, 51-68.

Funez, José Antonio. 2003. "El Modernismo en Honduras: la Obra Narrativa de Froylan Turcios." Tesis doctoral, Universidad de Salamanca.

Gold, Janet. 2000. El Retrato en el Espejo: Una biografía de Clementina Suarez. Tegucigalpa: Editorial Guaymuras.

Irwin, Robert McKee. 2000. "The Famous 41: The Scandalous Birth of Modern Mexican Homosexuality," Gay and Lesbian Quarterly, 6 (3): 353-376.

Manrique, Jaime. 1999. Eminent Maricones: Arenas, Lorca, Puig and Me.Madison: University of Wisconsin Press. 
Medina Durón, Juan. 1973. "El tema de la muerte en la novelística de Froylán Turcios”. (Tesis de grado). Tegucigalpa, Escuela Superior del Profesorado "Francisco Morazán".

Méndez Fuentes, Armando. 1991. "Charla Sobre Froylan Turcios En APH.” El Heraldo, Tegucigalpa, 31 de enero. . 1952. "El Maravilloso Oscar Wilde." La Epoca, Tegucigalpa.

Mejía, Medardo. 1980. Froylán Turcios en los campos de la estética y del civismo. Tegucigalpa, Editorial Universitaria.

Salinas Paguada, Manuel y Galel Cárdenas Amador. 1993. "Introducción, selección, y notas." En Manuel Salinas Paguada y Galel Cárdenas Amador El Circulo del Cobre: Antología del Cuento Erótico Centroamericano . Tegucigalpa: Lithopress Industrial, p. 1.

Sevilla, Luis Hernán. 1966. "Homosexualidad y Poesía." Semáforo, Tegucigalpa, 23 de julio.

Sosa, Roberto. 1987. "La Generación de La Dictadura.” En Rigoberto Paredes y Manuel Salinas Paguada, editores, Literatura Hondureña. Tegucigalpa: Editores Unidos, pp. 172-187.

Tábora, Rocio. 1995. Masculinidad y Violencia en la Cultura Política Hondureña Tegucigalpa: CEDOH.

Turcios, Froylan. 1940. "La Vida del Pasado." Revista Ariel, No. 77 (1 de noviembre), p. 1922.

Vallejo, Fernando.1992. Cartas de Barba-Jacob. Bogotá: Revista Literaria Gradiva.

Villars, Rina. 1999. "La Homosexualidad como Fenómeno Sociocultural." En Blanca Guifarro, compiladora, Antología: Entre Amigas, (1992-1997). Tegucigalpa: Guardabarranco, pp. 80-86.

Weeks, John. 2002. "Sexuality and History Revisited." En Kim M. Phillips y Barry Reay, editores, Sexualities in History: A Reader. New York: Routledge, pp. 27-41.

Wiesner-Hanks, Merry. 2001. Gender in History. London: Blackwell Publishers.

Wrathall, John D. 2002. "Reading the Silences Around Sexuality." En Kathy Peiss, editora, Major Problems in the History of American Sexuality. Boston: Houghton Mifflin, pp. 16-23.

Zúñiga Huete, Angel. 1949. Cartas: Una actitud y una senda, veleidades de un veleta México: sin editorial.

\section{NOTAS}

\footnotetext{
${ }^{1}$ Este ensayo representa sólo apuntes mínimos para un proyecto biográfico que llevara muchos años. Carta, Armando Méndez Fuentes a Darío Aquiles Euraque, de Nueva York a Nueva Orleans, 15 de febrero de 1968. Archivo, Armando Méndez Fuentes, en adelante (AAMF).

${ }^{2}$ Carta, Armando Méndez Fuentes a Merceditas Turcios, de Nueva York a Tegucigalpa, 1 de abril de 1968. (AAMF).
} 
3 "Acta de entrega de los documentos y cartas a don Armando Méndez Fuentes por parte de Mercedes
Turcios Vda. de Cubas Alvarado, con sus respectivas firmas y con la firma de los testigos Visitación
Padilla, escritora, y el pastor adventista Roberto G. Jones. En Tegucigalpa, año 1952" en Álbum
Empastado de Correspondencia para y de Froylan Turcios. (AAMF).
${ }^{4}$ Sobre la problemática del genero y sus metodología en Honduras, consulte Gold (2002) pp. 21-24.
(AAMF).
5 Sobre Proust y Turcios, declara Funez, "En cuanto a la influencia de la obra de Proust en Turcios,
sinceramente le diré que, al menos directamente, no encuentro ninguna. La obra de Proust era demasiado
moderno para impresionar a Turcios, que tenia predilección especial por los autores decadentes (Lorrian,
Laforgue, Villers de L'isle Adam, Pierre Louys, Loti, D'Annunzio, Valle-Inclan, Maeterlinck y Wilde). De
Wilde, que usted conocerá muy bien, hay una obra de teatro que influye mucho en Turcios, es "Salome"
(1891), sobre todo lo relacionado con el tema de la `mujer fatal"”. Comunicación Personal.
${ }^{6}$ En el 2000, en Tegucigalpa entreviste a ambos sobre el tema.
${ }^{7}$ Carta, Armando Méndez Fuentes a Manuel Flores, de Nueva York a Michigan, 6 de diciembre, 1991. (AAMF).

8 "Morar con el Divino Quijote". Este poema, quizás redactado en 1998, se encuentra al final de un ensayo titulado, "El Divino Quijote." Este ensayo retoma también el tema del arrepentimiento. Dice, "por su amor infinito y el perdón de mis pecados eficazmente debemos aceptar humildes con mis hermanos amados la necesaria conversión al Divino Quijote que existía antes de la cosmología...." (AAMF).

${ }^{9}$ Zúñiga Huete (1949), pp. 42-50. Huete en esta semblanza empleo el seudónimo de Serafín García. El historiador Ramón Oquelí, autoridad sobre estos cosas, nos aseguró que Zúñiga Huete utilizaba dicho seudónimo. La vida intima del poeta Rafael Heliodoro Valle aun no se ha abordado. Recientemente se publicaron cartas cruzadas entre Valle y el poeta colombiano Porfirio Barba Jacob que evidencian una pronunciada orientación por parte de Valle hacia las aventuras homosexuales de Barba Jacob. (Vallejo 1992), pp. 109-111, 118-122, 123-127, 128- 136-146 y 152-160. Agradezco al poeta hondureño Oscar Acosta, autor de una biografía de Valle publicada en 1964, esta referencia.

${ }^{10}$ Sevilla Gamero y Méndez Fuentes estaban al tanto de códigos clandestinos homosexuales que facilitaban comunicación entre si. En una carta de 1965, Sevilla Gamero declaro, ¿Que si pertenezco a los `41'? - Si, supongo que si...." Carta, Luis Hernán Sevilla Gamero a Armando Méndez Fuentes, Tegucigalpa a Nueva York, setiembre 20, 1965. (AAMF). Suponemos que la referencia es los "famosos 41" en la historia moderna del homosexualismo en México de 1901 en delante. (Irwin 2000).

${ }^{11}$ Sevilla Gamero (1966).

${ }^{12} \mathrm{El}$ archivo que heredamos de Méndez Fuentes y su biblioteca personal registran amplios detalles y pistas para darle seguimiento a numerosos nexos entre su vida literaria y el contexto de la "revolución sexual" de la época. Para una perspectiva general de ese contexto, ver a Allyn (2001).

${ }^{13}$ Carta, Luis Hernán Sevilla Gamero a Armando Méndez Fuentes, Danlí a Nueva York, 13 de marzo de 1985. En un fragmento de otra carta sin fecha, Sevilla Gamero le declara Méndez Fuentes, "¿Por qué no te decides a dar a la publicidad tus "Lotos del Pantano"? Ya te lo he dicho muchas veces: 'Santo que no es conocido, no es venerado'.” (AAMF).

${ }^{14}$ El esfuerzo de Méndez Fuentes fue verdaderamente vanguardista, especialmente en el contexto del conservadurismo que reinaba en las décadas de 1960 y 1970 sobre la investigación de la historia de la sexualidad aun en los países mas desarrollados. Wiesner-Hanks (2001), p. 208.

${ }^{15}$ Esta incineración de correspondencia se asemeja a rituales en contextos de amores y romances entre mujeres en los EE.UU. Freedman (2001).

${ }^{16}$ En Honduras, no existe una historiografía sobre la hetero- u homo- sexualidad en sí. Existen solo observaciones bastante generales. Ver a Rina Villars (1999). Aun en la literatura se carece en este sentido. "Parece ser que el tema del erotismo en el marco de la sociedad nacional causa aún todavía ciertas reacciones de rechazo, más que de entendimiento sobre el fenómeno de la modernidad." Salinas Paguada y Cárdenas Amador (1993), p. 1. 
